\title{
O Espaço Pré-Universitário Popular Povo Novo: a problematização da Prática Educativa priorizando a Emancipação Humana
}

\author{
El Espacio Popular Pre-Universidad Nueva Gente: la problematización de \\ la Práctica Educativa Priorizando la Emancipación Humana
}

\author{
The Popular Pre-University Space Povo Novo: the problematization od \\ Educational Practice Prioritizing Human Emancipation
}

\author{
Adriana Silveira Coronel ${ }^{1}$ \\ Alexandre da Silva Borges ${ }^{2}$ \\ Vilmar Alves Pereira ${ }^{3}$
}

\begin{abstract}
Resumo
O presente artigo problematiza o espaço pré-universitário a partir de conceitos da Educação Popular, tendo como pano de fundo a comunidade de Povo Novo/RS. O projeto em questão está vinculado ao Programa de Auxílio ao Ingresso nos Ensinos Técnico e Superior (PAIETS-FURG), e teve seu começo a partir da inquietação de membros comunitários já ingressantes no mundo acadêmico. Na perspectiva da Educação Popular, preconizada por Paulo Freire (2011, 2015), endossada por Gadotti (2012), Brandão (1985, 2006), Arroyo (2012) entre outros, fica respaldada uma ação educativa integral capaz de contribuir para uma formação humana, crítica, reflexiva e emancipatória. O primeiro curso pré-universitário na localidade do $3^{\circ}$ Distrito do Rio Grande/RS (Povo Novo) pode ser visto como um campo fértil para a análise da prática educativa, onde a esperança e emancipação dos sujeitos são os princípios fundamentais, para além da transmissão tradicional dos conteúdos disciplinares.
\end{abstract}

Palavras-Chave: Educação Popular; Pré-Universitário; Povo Novo/RS; Emancipação Humana; PAIETS.

\section{Resumen}

Este artículo discute el espacio preuniversitario basado en conceptos de Educación Popular, teniendo como base a la comunidad de Povo Novo / RS. El proyecto en cuestión está vinculado al Programa de Asistencia para la Admisión a la Educación Técnica y Superior (PAIETS-FURG), y comenzó con la preocupación de los miembros de la comunidad que ya ingresan al mundo académico. En la perspectiva de la Educación Popular, defendida por Paulo Freire (2011, 2015), respaldada por Gadotti (2012), Brandão (1985, 2006), Arroyo (2012), entre otros, se apoya una acción educativa integral capaz de contribuir a una formación humana. , crítico, reflexivo y emancipatorio. El primer curso preuniversitario en el 3er Distrito de Río Grande / RS (Povo Novo) puede verse como un campo fértil para el análisis de la práctica educativa, donde la esperanza y la emancipación de los sujetos son los principios fundamentales, además de la transmisión contenido disciplinario.

\footnotetext{
${ }^{1}$ Graduada em Pedagogia Licenciatura Plena pela Universidade Federal do Rio Grande - FURG. Educadora da disciplina de filosofia no curso preparatório Pré-Universitário Popular Povo Novo. Professora efetiva da Educação Básica no município de Pelotas .E-mail: adrianacoronel_@ hotmail.com

${ }^{2}$ Doutorando e Mestre em Educação, pelo Programa de Pós Graduação em Educação da Universidade Federal de Pelotas (UFPel); Graduado em História com Ênfase em Patrimônio Histórico e Cultural, pela Universidade Federal do Rio Grande (FURG), Educador pelo Programa PAIETS (FURG).

${ }^{3}$ Filósofo. Mestre e Doutor em Educação, Educador Popular e Ambiental. Coordenador do Programa de PósGraduação em Educação Ambiental da Universidade Federal do Rio Grande (FURG); Professor e Pesquisador no Instituto de Educação e nos Programas de Educação (PPGEDU) e Educação Ambiental (PPGEA) da Universidade Federal do Rio Grande- FURG. Editor Chefe da Revista Eletrônica do Mestrado em Educação Ambiental-REMEA. vilmar1972@gmail.com
} 
Palabras clave: Educación popular; Preuniversitario; Povo Novo / RS; Emancipación humana; PAIETS.

\begin{abstract}
This article discusses the pre-university space based on Popular Education concepts, having the community of Povo Novo / RS as a background. The project in question is linked to the Assistance Program for Admission to Technical and Higher Education (PAIETS-FURG), and began with the concern of community members already entering the academic world. In the perspective of Popular Education, advocated by Paulo Freire (2011, 2015), endorsed by Gadotti (2012), Brandão (1985, 2006), Arroyo (2012), among others, a comprehensive educational action capable of contributing to a human formation is supported, critical, reflective and emancipatory. The first pre-university course in the 3rd District of Rio Grande / RS (Povo Novo) can be seen as a fertile field for the analysis of educational practice, where the hope and emancipation of the subjects are the fundamental principles, in addition to the traditional transmission of disciplinary contents.
\end{abstract}

Keywords: Popular Education; Pre-University; Povo Novo / RS; Human emancipation; PAIETS.

\title{
1. Introdução
}

Povo Novo fica localizado entre os municípios gaúchos de Rio Grande e Pelotas, às margens da BR-392. Trata-se de uma comunidade distrital, pouco distante dos centros urbanos, que acabou sendo lesada pelo atraso no estabelecimento de instituições formais de ensino público. Há poucas décadas o acesso à educação formal se restringia apenas ao ensino fundamental, sendo que a oferta para muitos dos habitantes limitava-se ao $4^{\circ}$ ano.

Nesse sentido, infere-se que a precariedade dos processos de ensino e aprendizagem refletiu no contexto cultural de toda uma comunidade, acarretando numa possível falta de valorização de sua identidade, enquanto sujeitos locais, bem como num encurtamento de seus horizontes. Essas consequências geram ainda mais angústias e distanciamentos do ambiente escolar, assim como potencializa um relativo entrave escolar (FEITOSA, 2011). Tais obstáculos no âmbito educacional são capazes de definir não apenas um déficit cultural, mas também econômico, alicerçado numa baixa produção pecuária e agrícola familiar.

Com a ampliação das escolas e das ofertas de ensino houve a necessidade do ingresso de professores dos centros urbanos, os quais não tinham um pertencimento às nuances identitárias, de certa forma negligenciando a cultura pongondó ${ }^{4}$ ainda mais. Cabe dizer que tais processos aqui colocados são hipóteses acerca do processo educacional, não apenas da localidade em questão, mas também dos demais contextos ruralizados, que se estabelecem de maneira natural (não intencional por parte dos professores), num quadro relativamente pronto na estrutura social e política.

\footnotetext{
${ }^{4}$ Termo usado pelos locais para designar o morador do Povo Novo, que nasceu ou habita o local, segundo a tradição oral.
} 
Povo Novo é tão antigo quanto seu município, Rio Grande (1737). Muitos dos moradores mais velhos da localidade afirmam que a origem do Povo Novo enquanto comunidade estabelecida é ainda mais longínqua. Maria Bertuline Queiroz (1987), historiadora que se debruçou na história da região, no entanto, aponta as invasões castelhanas no Rio Grande como baliza para o surgimento do povoado, já que muitos dos portugueses que teriam fugido da Vila do Rio Grande de São Pedro teriam procurado na Ilha da Torotama (povoado já existente) um refúgio. Com o "inchaço populacional" ter-se-ia criado o Pueblo Nuevo Del Torotama, então Povo Novo. Já nos atos da prefeitura do Rio Grande, sobre a anexação do povoado enquanto distrito, consta que "Pela Lei Provincial n. ${ }^{\circ}$ 35, de 06-05-1846 e Ato Municipal n. ${ }^{\circ}$ 29, de 14-07-1906, foram criados os distritos de Taim e Povo Novo, anexados ao município do Rio Grande."

Ainda segundo Queiroz (1987), logo após a invasão e a organização do novo povoado, houve um longo período de miséria, já que os habitantes que ali se refugiaram não eram os mais favorecidos economicamente. Para aqueles que a situação econômica era mais favorável, as condições de fuga e/ou resistência eram mais facilitadas. Eis uma versão sobre o princípio da comunidade do Povo Novo, sob o cunho acadêmico. Porém outras narrativas apresentam ainda outras vias - objeto que carece maior estudo.

Hoje, a comunidade mescla nuances rurais com traços urbanos. Pode-se dizer que a localidade está centralizada na Praça Coronel Marcelino, onde no seu entorno reúnem-se a Sub-Prefeitura, o posto de saúde e a Igreja Católica Nossa Senhora das Necessidades e o salão Paroquial, característica da colonização expressa pela disposição dos prédios. Na rua principal, Major Assumpção está fixada a Escola Estadual de Ensino Médio Alfredo Ferreira Rodrigues (a qual leva o nome do personagem histórico nascido no Povo Novo), que também fica às margens da BR-392 e recebe, na atualidade, as obras do novo prédio escolar, derivado da duplicação da via (que demoliu o antigo prédio). É importante ressaltar também o engenho de arroz (Camil), localizado na comunidade, o qual emprega diversos dos habitantes.

Grande parte dos moradores, que não encontram a oportunidade de trabalhar em Povo Novo (seja no engenho de arroz, no posto de gasolina, nos mercados locais, nos setores agropecuários e/ou enquanto autônomos etc.) parte para os centros urbanos em busca de garantias trabalhistas, assinando suas carteiras no ramo do comércio (principalmente em Pelotas), ou no

\footnotetext{
5 Informação cedida pela prefeitura do Rio Grande/RS, encontrada no IBGE pelo endereço https://cidades.ibge.gov.br/brasil/rs/rio-grande/historico
} 
setor portuário/naval/industrial, em Rio Grande. Ainda sobre as formas de renda dos pongondós, vale ressaltar as tradicionais bancas na beira da estrada, as quais vendem alguns dos produtos advindos das plantações da região. As réstias de alho e cebola feitas com junco se destacam - prática que envolve todo um saber e um modo-de-fazer tradicional.

Nesse ínterim, é possível entender algumas demandas locais na busca de estabilidade econômica ou no desenvolvimento de um pertencimento sempre atravessado pela necessidade de buscar nas "cidades" o conteúdo faltante para o suprimento de uma melhor condição de vida. Para muitos daqueles que se formaram na única escola de ensino médio do Povo Novo, a distância preconcebida do acesso à universidade extrapola as condições educacionais. Ou seja, as dificuldades encontradas no "retorno" aos estudos, ou num planejamento para o enfrentamento do Exame Nacional do Ensino Médio (ENEM), podem estar embrenhadas na falta de confiança dos sujeitos em si mesmos, advindos de um trajeto de obstáculos relevantes, como a distância física de algumas regiões do Povo Novo de seu centro, impossibilitando, outrora, a continuidade de suas formações (hoje com melhor acesso para aqueles que estão na escola, com o uso de ônibus escolares, o que em tempos anterior não havia). Uma resposta à esta demanda se tornou emergencial.

Embora o panorama histórico visto, a perspectiva freireana aponta que a esperança é uma chama que sempre arde diante das opressões nos diferentes contextos sociais. Foi imbuído desta essência que alguns graduandos e graduados, moradores dessa comunidade, tornaram-se educadores do Pré-Universitário Popular Povo Novo (PUPPN), numa parceria com o PAIETS ${ }^{6}$, com mais de dez polos de atuação, coordenado pelo Prof. Dr. Vilmar Alves Pereira da Universidade Federal do Rio Grande (FURG). O PAIETS está alicerçado nas concepções da Educação Popular, a qual atenta para uma formação humana, mais integral, em comparação ao ensino tradicional institucionalizado. Trata-se, também, de uma formação politizadora.

\section{O Pré-Universitário Popular Povo Novo: origem e características}

Observando o contexto histórico mencionado, o projeto em questão teve como objetivo geral o despertar da comunidade para o reconhecimento de si, o pertencimento local, o espírito crítico e o entendimento do conhecimento para a emancipação humana. Para tanto,

\footnotetext{
${ }^{6}$ Programa de Auxílio ao Ingresso nos Ensinos Técnico e Superior.
} 
preocupou-se não apenas em atender a demanda do acesso à universidade a partir da transmissão dos conteúdos preestabelecidos, mas também provocar o empoderamento dos educandos, promovendo uma resposta à polaridade do arquétipo do professor enquanto opressor, dada uma hierarquia imposta pela educação tradicional - além de uma valorização/sensibilização mútua, mas reafirmada pelos educandos, em relação aos seus iguais - característica da Educação Popular, já que esta possui um viés coletivo.

Referente ao ano de 2018, as atividades do Pré-universitário começaram em novembro de 2017, onde foi elaborado de maneira conjunta, entre os voluntários, um projeto, exigido pelo coordenador do PAIETS, professor Vilmar Alves Pereira, como forma desse programa poder conhecer a historicidade da comunidade e as justificativas para sua implementação. $\mathrm{O}$ mesmo foi enviado ao programa no final da primeira quinzena de dezembro do mesmo ano. $\mathrm{E}$ após receber a aprovação para sua implementação passou-se então a ser planejada a forma como se dariam as aulas. Assim cada educador passou a ser responsável por desenvolver seu cronograma com a ordem cronológica de seus conteúdos, a partir das disciplinas em que se tinha educadores voluntários, que inicialmente eram as de português, espanhol, literatura, matemática, física, química, filosofia, sociologia, história, geografia, atualidades.

O período de cada aula ficou estipulado como sendo o horário das 19 horas às 21 horas e 45 minutos, com duas disciplinas durante esse período. Sendo que, por escolha de duas educadoras, havia aulas até às 22 horas, as mesmas dividiam as disciplinas das letras. Uma com espanhol e literatura e a outra com português e redação. Essas aulas eram dadas nas segundas-feiras, sendo alternadas de maneira quinzenal. E para que fosse dado conta todas as disciplinas, ocorreram aulas aos sábados, no horário das 9 horas às 11 horas e 30 minutos, onde alternava-se química e física também de maneira quinzenal. O restante das disciplinas, que eram as de filosofia, sociologia, geografia, história, atualidades e matemática, distribuíram-se no decorrer da terça-feira, quarta-feira, quinta-feira e sexta-feira. Nesse momento não havia educador para biologia.

A formação desses educadores que ministraram as aulas era bem variada: Geografia, com o educador Diego Noda, com formação em Geografia licenciatura e mestrado em andamento $^{7}$; História, com Cauê Braga dos Santos, graduando em história bacharelado; Filosofia, com Cananda Borges, formação em filosofia; Física, com Tairson Sena, graduando em física bacharelado; Química, com Pedro Borges, graduando em farmácia e bioquímica; Sociologia, com Daniele Castanheira, formada em sociologia; Matemática, com Roberto

\footnotetext{
${ }^{7}$ As informações referentes à formação de cada educador trazem o contexto de início das atividades do Projeto, logicamente alteradas visto o tempo presente.
} 
Schim, graduando em Engenharia da Automação; Português/redação, com Jéssica Pereira, graduada no curso de Letras/espanhol e com pós-graduação em andamento; Literatura/espanhol, com Fernanda das Neves, graduanda no curso de letras/espanhol; Atualidades, com Adriana Coronel, graduanda na Pedagogia, a qual também era a coordenadora do projeto nesse período inicial (2018), com a função de frequentar todas as aulas, organizar reuniões, eventos, horários, atender as demandas rotineiras da turma e dos educadores para o bom andamento das aulas e acompanhar os educandos individualmente no sentido de evitar a evasão.

No segundo semestre de 2018 algumas alterações ocorrem no quadro de educadores dispostos a ministrarem as disciplinas ofertadas no projeto. Como exemplo, a disciplina de História, a qual passa a ser problematizada e mediada pelo educador Alexandre da Silva Borges, com Bacharelado em História, mestrado em Educação e doutorado em Educação em andamento.

A partir da distribuição de disciplinas e organização das aulas, que se deu no período do mês de janeiro de 2018, e conforme já colocado, cada educador teve autonomia para estabelecer os conteúdos partindo da análise do Ministério da Educação - Portal do MEC, que trata das datas em que ocorrem as inscrições e seus processos, bem como da análise de conteúdo disponível no site https://enembrasil.com.br, que esclarece os conteúdos a partir do modelo do ensino médio. Toda essa estrutura de organização foi amparada pelo apoio mútuo dos educadores em encontros individuais com a coordenadora do grupo e por reuniões entre todos os educadores, semanalmente, porém sob forma de agendamento.

A organização disciplinar e de seus conteúdos procurou estar sempre atrelada ao espírito da Educação Popular, compreendendo a realidade dos educandos em seus aspectos cultural, social, político e econômico. No sentido freireano de desenvolver um olhar cuidadoso acerca da realidade social de cada sujeito, assim já nas inscrições para o ingresso dos educandos, que se deu na segunda quinzena do mês de fevereiro, as fichas de inscrição buscaram observar alguns detalhes: a posição familiar em que o inscrito se encontrava, sua renda, sua disponibilidade de horário para frequentar as aulas, a perspectiva que tinha diante da busca pelo curso, sua idade, tempo que permaneceu na escola formal, as dificuldades referentes às disciplinas, o curso ao qual o educando gostaria de ingressar na universidade. Na apreensão desse panorama, deu-se início às aulas, no início de março de 2018.

Para que fossem compreendidos os significados da Educação Popular dentro de cada disciplina, cada educador foi planejando suas aulas, em meio a conversas e compartilhamento de experiências e saberes sobre a docência. Nesse sentido, em abril de 2018 houve o encontro 
de educadores populares, ofertado pelo programa PAITES na Universidade Federal do Rio Grande - FURG, onde os educadores tiveram a oportunidade de compreender o sentido da prática docente a partir dos conceitos da educação popular, conhecendo um pouco mais da perspectiva freireana que encabeça de maneira teórica a organização de todos os contextos pré-universitários os quais o PAITES abarca.

Para o início das atividades foi estabelecida parcerias relevantes para o andamento do projeto. No atendimento de questões materiais e físicas, houve respectivamente o apoio da Escola Estadual de Ensino Médio Alfredo Ferreira Rodrigues, com a cessão de um quadro negro e giz, e a Comunidade Católica Nossa Senhora das Necessidades, com o espaço (salas de aula e classes).

A parceria com a Universidade Federal do Rio Grande, se deu por meio da vinculação com o PAIETS, onde o projeto local teve as bases necessárias para conciliar as demandas da comunidade do Povo Novo com a estrutura de um programa Pré-Universitário. Logo, as teorias até então vislumbradas pelos educadores puderam, de fato, serem aprofundadas a partir de leituras, discussões e partilhas acerca da Educação Popular.

Os trâmites de seleção e ingresso de educadores se deu partindo de convite a um número reduzido de moradores da comunidade que possuíssem vinculação com a universidade (graduandos), ou já graduados em cursos de licenciatura e/ou bacharelado que tivessem equivalência às disciplinas previstas num curso pré-universitário.

Anterior ao processo de matrícula, houve a divulgação do PUPPN em locais públicos e comerciais, como por exemplo no Posto de Saúde e Mini Mercados da localidade, bem como nas redes sociais (Facebook ${ }^{8}$ e Whatsapp). Além destes mecanismos, pode-se dizer que o boca à boca, meio de propagação informativo comum na localidade, contribuiu de maneira significativa.

A primeira matrícula contou com 18 sujeitos:

\footnotetext{
8 Para uma melhor divulgação e organização das atividades do PUPPN foi criada uma página específica:
} https://www.facebook.com/PreUniver.Popular.PN/ 


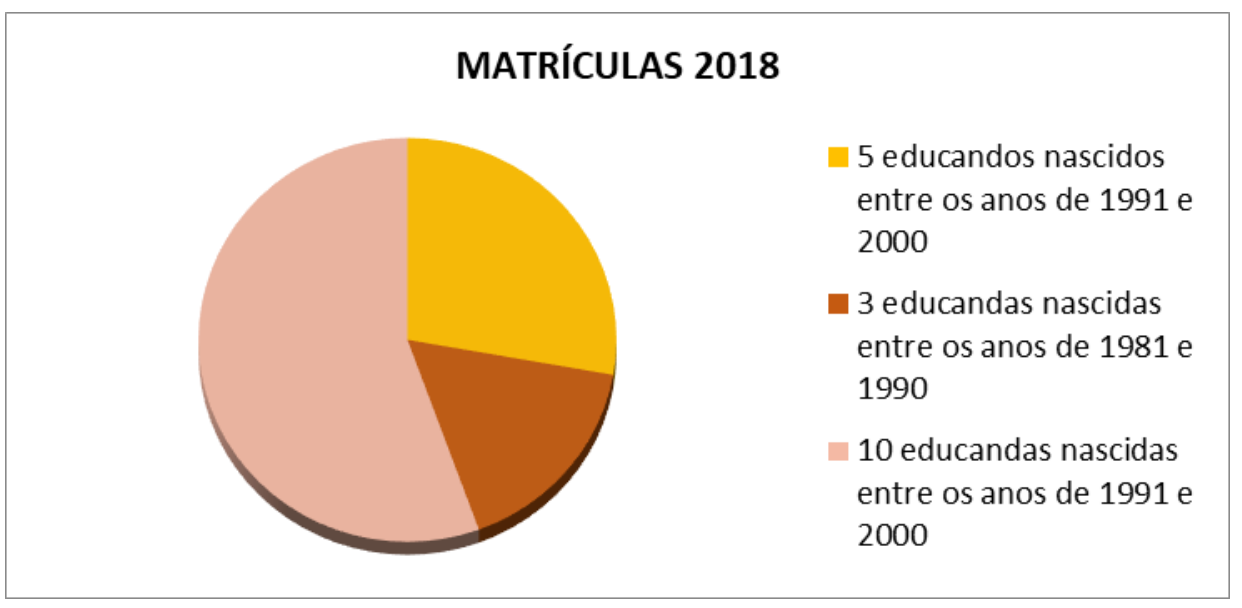

Figura 1 - Gráfico de matrículas em 2018. Fonte: dados da pesquisa.

No processo de reabertura das inscrições, devido às vagas ociosas, ingressaram dois educandos (entre os cinco que constam no gráfico) para o segundo semestre letivo (julho a novembro de 2018). Contudo, no término das atividades, apenas nove educandos (três do gênero masculino e seis do gênero feminino) mantiveram-se junto ao curso, podendo então participar do Exame Nacional do Ensino Médio (ENEM).

Dos nove educandos concluintes, até a presente data, teve-se os seguintes ingressos:

Ensino técnico

- uma educanda para o curso de Téc. Agropecuária (CAVG - IFSul/Pelotas);

\section{Ensino Superior}

- uma educanda para o curso de Licenciatura em Matemática (FURG);

- uma educanda para o curso de Licenciatura em Geografia (FURG);

- um educando para o curso de Engenharia da Computação (FURG);

- um educando para o curso de Licenciatura em Química (CAVG - IFSul/Pelotas).

Identifica-se que mais de $50 \%$ da turma concluinte conseguiu ingressar no ensino técnico e/ou superior.

Ainda, na leitura do gráfico, pode-se inferir que o Pré-universitário contou com uma maior adesão por parte do gênero feminino. Acredita-se que desde o processo de matrícula até o término das aulas, o gênero feminino esteve presente em maior número devido à ocupação por parte dos sujeitos do gênero masculino em ambiente de trabalho no meio rural. Essa inferência destaca também o gênero feminino atrelado às funções do ambiente doméstico, o que, talvez, possibilita uma maior flexibilidade de horários. Esse quadro pode demarcar uma particularidade da comunidade em que o projeto se insere. Contudo, converge para tal 
panorama a postura da mulher enquanto sujeito multifacetado e predisposto, ainda em busca de uma equidade social que, neste caso, vem a ocorrer por parte da emancipação, não apenas humana, mas também educacional.

Pensando nesse cenário, emerge enquanto reflexão um "pensar" mais atento à questão de gênero, buscando refletir sobre a inserção dos homens no Pré-universitário e as condições de permanência desses sujeitos. A questão da "desistência", diferente do ingresso, extrapola a condição de gênero, já que para ambos se percebe certa dificuldade na continuidade dos estudos. Tais inferências traduzem constatações ainda incipientes nos estudos acerca dos espaços pré-universitários, relevantes a um olhar mais apurado e cuidadoso em prol dos pressupostos de uma Educação Popular, enquanto uma pedagogia mais sensível e orgânica.

Quanto às diretrizes pedagógicas do projeto, pode-se dizer que as teorias da Educação Popular justificam o movimento de troca desenvolvido no Pré-universitário Popular Povo Novo, no momento em que foram utilizadas nuances do método de Freire para alfabetização de jovens e adultos, nas práticas em favor da emancipação e libertação dos sujeitos, ressignificando o ato de aprender. Tanto na alfabetização de adultos como em qualquer transmissão (tradicional) ou troca de conteúdo é possível avançar para além dos mesmos, principalmente quando amparados pelos construtos teóricos de freire e demais pensadores de uma educação sensível. Dessa forma, o educador utiliza o conhecimento dos conteúdos para questionar e impulsionar os educandos, inserindo seus conceitos na realidade dos sujeitos, como forma de intervenção a sua criticidade, objetivando desconstruir a visão ingênua e engessada de determinados fatos ou conceitos acerca de conhecimentos adquiridos durante o período escolar.

Com esta postura pedagógica passa-se então a haver a intenção, por parte do educador, de que o educando transforme o seu contexto de vida a partir da construção de uma nova visão de mundo através do desenvolvimento do senso crítico. A proposta pedagógica para o Pré-universitário Povo Novo observa os conteúdos estudados nas disciplinas escolares como elementos a serem inseridos, por meio do senso de realidade, na prática cotidiana dos sujeitos. Através do relato dos educandos foi observado que os mesmos não entendem os conceitos já estudados como parte da sua vida. Assim os princípios de Freire pensados para lidar com a Educação Popular, age em favor de uma abertura significativa ao âmbito científico, agora sob nota de coerência. 
Diferente da transmissão dos conteúdos em pré-universitários particulares direcionados apenas como ferramenta para o êxito na prova do Enem, sem questionamento diante das verdades já estabelecidas nos mesmos - a relação do educador e o educando em âmbito popular costuma se dar de maneira mais informal, estabelecendo certa horizontalidade, cercada por sentimento e emoção, o que traz uma aproximação de ambos polos, oportunizando a desinibição do educando diante da sua linguagem, fazendo com que o mesmo manifeste-se verbalmente durante aula, contribuindo com sua opinião diante da realidade.

O processo de conscientização caminha junto com a aprendizagem, contribuindo para leitura de mundo, pois desconstrói a aprendizagem mecânica, rompendo com o conhecimento que é estabelecido como verdade absoluta e criando a possibilidade de hipóteses atrelando o uso dos saberes comunitários, tradicionais e/ou ordinários.

\section{Sobre a Educação Popular: aspectos Teórico-Metodológicos}

Pensar a episteme da Educação Popular significa refletir sobre a sua natureza e nas relações que os sujeitos estabelecem com ela. Uma postura indagativa, a partir do próprio conhecimento de mundo individual, auxilia no processo de busca em torno desse saber.

Assim, a Educação Popular também se pauta na construção epistemológica, a partir de conhecimentos específicos que venham ao encontro da prática por ela propagada.

Moacir Gadotti nos diz que:

Um dos princípios originários da educação popular tem sido a criação de uma nova epistemologia, baseada no profundo respeito pelo senso comum que trazem os setores populares em sua prática cotidiana, problematizando-o, tratando de descobrir a teoria presente na prática popular, teoria ainda não conhecida pelo povo, problematizando-a também, incorporando-lhe um raciocínio mais rigoroso, científico e unitário (2012, p. 14).

Nesse sentido, Gadotti indica que a teoria da Educação Popular prevê um corpus bem definido e consciente, engajado com a libertação do saber.

Concomitante a isso, as palavras de Brandão (2006) trazem a compreensão de que ao longo do processo histórico social foi retirado dos sujeitos o direito ao conhecimento. Colocado pelo autor, esse cerceamento se deu no período em que a sociedade passou a 
dividir-se pelas condições sociais. Sendo assim "o saber" que estava contido nas comunidades construídas através das relações com a natureza, passa por um processo de divisão, e o início das construções das cidades vai dando um rumo a este grande poder, apossando-se deste. Criam-se, então, os senhores das cidades, multiplicando os ofícios (modos de trabalho), desenvolvendo assim uma educação para tal.

Conforme Brandão (op.cit), ao longo dos tempos "o saber" foi sendo dividido entre os que possuíam uma cultura variada, o erudito, e as comunidades que mantinham sua relação com a natureza. O primeiro passou então a tornar-se oficial detentor da verdade, alimentado pela ganância; o saber passou a ser um segredo, um privilégio e um domínio. Enquanto a segunda, as comunidades tradicionais, bem como os indígenas, mantinha-se de forma enfraquecida e desvalorizada pelos eruditos - permaneciam entre os escravos, nas lavouras, nas construções entre outros ambientes em que se concentrava as comunidades, fazendo com que estes sujeitos das camadas populares não reconhecessem sua instrução e sua própria cultura, provocando autodesvalorização dos mesmos.

Refletir sobre a origem das camadas populares é alicerce para quem se propõe a ser um(a) educador(a), visto que a partir destes fatos, observa-se uma das funções da educação popular: tentar devolver àqueles que hoje encontram-se à margem do poder e presos ao trabalho, o que um dia lhes foi roubado, restituindo-lhes o direito ao reconhecimento de si, dos seus saberes, da própria cultura e abrindo caminho para o conhecimentos de novos saberes e novas culturas sendo este um direito de todos e para todos.

No decorrer da construção histórico-social a negação ao direito ao reconhecimento de si, anulou a construção da identidade de muitos sujeitos, fortalecendo o medo de seguir seus sonhos, tolhendo a sua liberdade de fazer escolhas. Assim sendo, a atuação junto as camadas populares, possibilita ao educador contribuir para o reconhecimento da importância de seus saberes, instigando os sujeitos a se perguntar, o que são e o porquê encontram-se em determinado contexto social, político e econômico.

Brandão (op. cit., s/p) questiona: "Afinal, que outra é a matéria do educador senão a palavra?" É possível compreender nesse sentido, que o autor destaca a "palavra” como um elemento fundamental no processo educativo, que ela não deve ser apenas objeto de transmissão do conhecimento, mas um direito de expressão, que possui a função de desenvolver as habilidades do pensamento, de ser a promotora da criatividade, da 
aprendizagem, da inclusão e da socialização, movimentando o sentido do humano e devolvendo a riqueza às classes populares, que é o direito do "saber".

Miguel Arroyo (2012) converge com a teorização proposta por Brandão acerca da Educação Popular, quando fala sobre Outros sujeitos, outras pedagogias. Nessa obra, pode-se reconhecer as diferenças entre uma pedagogia instauradora, essência de uma educação humana e popular, e uma pedagogia regulada por um sistema de valores preestabelecidos socialmente, fatores estes que estão reservados aos muros escolares/institucionais. Tais conhecimentos formais, ao mesmo tempo em que são necessários, não podem configurar-se enquanto uma normatização da vida, pois seriam, desta forma, um saber colonizador. Ainda,

[a]s pedagogias escolares são as mais cercadas e fechada a definir critérios rígidos de validade e até de não reconhecimento da validade dos saberes, modos de pensar e de pensar-se, de aprender e de educar-se que os educandos levam às escolas e às universidades. As crianças e jovens populares até os adultos na EJA são obrigados a ocultar suas experiências sociais e as indagações e leituras que levam do trabalho e dessas experiências tão radicais. Até os militantes que vem de tensas experiências de lutas nos movimentos e que acumularam riquíssimas práticas e concepções pedagógicas são levados a ignora-las ou, ao máximo, servirão como matéria-prima para despertar o interesse por teorias sérias, científicas. Até o saber e a criatividade e as autorias docentes são controlados no fazer pedagógico. (p. 33)

Com isso, pode-se inferir que as condições de desenvolvimento dos sujeitos provenientes das camadas populares, em meio à educação escolar e/ou institucionalizada, podem ser limitadoras, já que negligenciam a identidade, o pertencimento e as origens dos educandos, potencializando uma autodesvalorização. Além disso, aqueles que vencem a trajetória escolar e até mesmo a carreira acadêmica, muitas das vezes desvestem sua roupagem primária/original, para se vestir de uma identidade produzida, que reprime e nega uma cultura própria, colocando outra, padronizada, em seu lugar. Tal reprodução, atrofiada de si para algo ideal, cegam os sujeitos de sua própria realidade e contexto social.

Na Educação Popular, o educador deve estar atento a essas nuances identitárias, prevendo possíveis distorções formativas, promovendo o reconhecimento do sujeito enquanto integrante do meio comunitário, onde o mesmo se origina e se insere. Para tanto, tem-se como base as palavras de Paulo Freire (2015, p. 94):

Como educador preciso de ir "lendo" cada vez melhor a leitura do mundo que os grupos populares com quem trabalho fazem de seu contexto imediato e do maior de que o seu é parte. O que quero dizer é o seguinte: não posso de maneira alguma, nas minhas relações político-pedagógicas com os grupos populares, desconsiderar seu saber de experiência feito. Sua explicação do mundo em que faz parte a compreensão 
de sua própria presença no mundo. E isso tudo vem explicitado ou sugerido ou escondido no que chamo "leitura do mundo" que precede sempre a "leitura da palavra".

A não-negligência, por parte do educador, frente à leitura de mundo de cada educando resulta num entendimento mais íntimo e sensível sobre a realidade de cada indivíduo em sala de aula. Além disso, identificar como os sujeitos recebem e refletem o conhecimento faz com que parâmetros perceptivos/cognitivos sejam dimensionados. Ou seja, a partir da vivência única e pessoal de cada educando, como o mesmo entende o que é dito? Esse entendimento é livre de uma colonização do pensar? Quão liberta é a percepção, dada as presilhas dos dogmas ocidentais, a partir da branquitude, da eurocentrização, da heteronormatividade, do ideal capitalista etc.?

Leonardo Boff, na celebre obra A águia e a galinha (1997), indica a padronização que os colonizados sofreram e ainda sofrem, assumindo uma cultura, um hábito social e político e, principalmente, um modo específico de produção e de consumo, o que se pode traduzir numa homogênese da condição humana aos princípios capitalista/ocidental. Esta unidade do Ser, alicerçada no convencional globalizado, pode ser percebida e trabalhada (desconstruindo-a) no âmbito da Educação Popular, após esta ser visualizada e questionada em cada educando.

Eis do que é imbuído o agente educador em meio popular: mediar a emancipação, a partir do sujeito e de sua própria consciência. A emancipação converge com o recontar da História, com a transposição dos ideais de classe, na antítese dos conhecimentos préestabelecidos. Entender cientificamente um conceito, partindo do chão do educando, é traduzir em coerência toda uma pedagogia sensível e ontológica. A Educação Popular converte o conhecimento de mundo em propulsão para a aquisição de novos conhecimentos, já que alia a particularidade dos "conhecimentos científicos" e "disciplinares" às particularidades e saberes locais, comunitários e individuais.

O movimento de mediação emancipatória que faz o educador em meio ao espaço formativo popular é coerente com sua formação sensível e/ou com sua origem. A sensibilidade do agente educador frente às nuances populares e sua postura dialógica refletem um sujeito preocupado com o seu meio social e com a equidade entre os grupos, atento às comunidades vulneráveis. Tal atenção, muitas das vezes, é consequência de uma experiência extensionista no âmbito universitário, que também leva em consideração a pesquisa e o ensino, porém, a partir da extensão. 
Paulo Freire, na obra Pedagogia do Oprimido (2011, p. 94), diz que "[a] educação que se impõe aos que verdadeiramente se comprometem com a libertação não pode fundar-se numa compreensão dos homens como seres vazios a quem o mundo "encha de conteúdos"”. Com isso, a mediação para a emancipação dos sujeitos deve levar em conta uma construção coletiva, alicerçada na diversidade, tendo como horizonte e utopia não apenas as demandas sociais, mas, e principalmente, as especialidades e a atividade de cada educando.

Para Gadotti (2012, p. 11),

[a] diversidade é a marca desse movimento de educação social, popular, cidadã, cívica, comunitária. Trata-se de uma rica diversidade que precisa ser compreendida, respeitada e valorizada. A primeira impressão que se tem é de fragmentação, mas se olharmos o conjunto desta obra, veremos que ela está unida - "cimentada", como diria Antonio Gramsci (1968) - por uma causa comum, chamada pelos movimentos sociais de "outro mundo possível". Essa diversidade tem em comum o compromisso ético-político com a transformação da sociedade, desde uma posição crítica, popular, política, social e comunitária.

Essa conduta faz da mediação (interferência) uma mediatização ${ }^{9}$, já que preocupa-se com a criticidade e com a conscientização do educando enquanto gerador de sua própria alteração perante um novo mundo. Nesse movimento, há uma troca constante, horizontal, e de contra-marcha à uma educação "bancária", a qual pode ser entendida enquanto a transmissão de conteúdos ao aluno/depósito. Freire ainda afirma: “[n]inguém educa ninguém, ninguém educa a si mesmo, os homens se educam entre si, mediatizados pelo mundo" (p. 95). Nessa percepção, a educação "bancária" estaria atrelada a uma postura de dominação, enquanto uma educação problematizadora estaria a serviço da libertação.

\section{Entre Vivências e Aprendizagens no PUPPN: breve relato de Emancipação Humana}

Na concepção do projeto, os educadores, embora alguns já estivessem engajados com a docência e até mesmo com a proposta da Educação Popular, não tinham dimensão das surpresas que teriam durante a jornada junto aos seus educandos.

\footnotetext{
9 “Os mecanismos de pedagogia mediatizada são especialmente úteis para ajudar os alunos a reorganizar os processos de pensamento e para a restruturação dos processos cognitivos. Os procedimentos mais utilizados pelos professores são: processos de questionamento; processos de transferência de conhecimentos; provocar ou solicitar justificações; enfatizar a ordem, a predictabilidade, a sistematização e a sequencialização de acções; processos de generalização; e o uso de estratégias cognitivas (processos de atenção, de memória e de problema solving" (FERREIRA, 2004, s/p).
} 
Pode-se dizer que a motivação inicial do engajamento das pessoas envolvidas na criação do PUPPN teve como pano de fundo a inquietação diante das fragilidades da comunidade pongondó, que se encontra distante do "assistencialismo" político, seja no âmbito social, cultural ou educacional. Essa essência inconformada é comum a um educador popular:

Partindo do fato de que a desigualdade não é um processo natural, Paulo Freire enfatiza que é preciso aguçar nossa capacidade de estranhamento, não se calar face as injustiças, desenvolver uma nova ética e uma nova racionalidade quanto aos valores a serem cultivados/preservados. (GOHN, 2002, p.66)

Com certa timidez, os educadores começaram suas aulas sem abordar questões que ultrapassassem os conteúdos previstos pelas suas disciplinas. Contudo, ao observar a grande introspecção dos sujeitos, fez-se necessário uma reflexão acerca dos motivos que os levavam a tal comportamento. Foi então que os educadores trouxeram a proposta de sensibilização dos educandos, problematizando o papel do professor e do aluno, predefinidos no âmbito formal de ensino, numa contraposição àquele ambiente de formação humana.

Para tanto, foi necessária uma provocação que estimulasse a reflexão sobre a igualdade entre todos aqueles que compartilhavam do mesmo espaço, ou seja, a sala de aula. Essa experiência despertou, nos educandos, o senso de liberdade e da percepção de si enquanto sujeito ativo, tanto no ambiente educacional quanto em sociedade, fomentando uma postura participativa, numa condição dialógica de aprendizagens. O método dialógico, de concepção freireana, faz jus à uma educação desmitificadora, que intenta o "desvelar" da realidade, o que é antagônico ao "método bancário" que “(...) nega os homens na sua vocação ontológica e histórica de humanizar-se" (FREIRE, 2011, p. 101).

Essa humanização parte da maneira que o educador apresenta uma postura política, engajada no compromisso social em prol do coletivo. É na coletividade que as arestas se aparam, numa quebra paradigmática. Para tanto, o sujeito educador deve apresentar-se não apenas de forma política e crítica no meio de ensino popular, mas também enquanto igual, na troca mútua de experiências sempre refletindo e questionando o status quo. Essa concepção destaca um ensinar que pode ser desinstitucionalizado, porém que não enfraquece o sentido de Educação: “[a] educação pode ser livre e, entre todos, pode ser uma das maneiras que as pessoas criam para tornar comum, como saber, como ideia, como crença, aquilo que é comunitário como bem, como trabalho ou como vida" (BRANDÃO, 1985, p.10). Por outro lado, "[a] educação é sempre uma certa teoria do conhecimento posta em prática, é 
naturalmente política, tem que ver com a pureza, jamais com o puritanismo e é em si uma experiência de boniteza" (FREIRE, 2015, p. 101) ${ }^{10}$.

A partir do senso de liberdade dos sujeitos envolvidos, desfez-se a homogeneidade da turma, a qual estava (pelo silêncio) presa a uma linearidade comportamental, criando-se assim uma heterogeneidade a partir da expressão da peculiaridade de cada educando. A sala tornava-se diversa! Nessa diversidade cada um pôde vivenciar e comungar de sua essência, compartilhando com seus semelhantes, vivências, expectativas, inseguranças e, principalmente, esperança. As aulas timbravam-se de vivas cores! Eis a "boniteza" da experiência!

\section{5. À guisa de conclusão}

O presente artigo buscou refletir sobre nuances da Educação Popular a partir da problematização do espaço Pré-Universitário Popular Povo Novo (PUPPN), no município do Rio Grande (RS), bem como as vivências do mesmo durante seu primeiro ano letivo (2018).

Diante desse propósito, pôde-se destacar as condições particulares de uma comunidade com características rurais e traços urbanos, a qual vê-se, muitas das vezes, negligenciada pelos poderes governamentais e institucionais frente às suas demandas. Neste caso, o projeto teve como foco suprir a necessidade da comunidade em relação ao ingresso no ensino técnico e superior. Através deste primeiro intento, foi possível fomentar nos sujeitos a criação de um grupo que, além de lutar pelos seus sonhos, construiu de maneira coletiva a criticidade, a autoestima, o estabelecimento de metas, o pertencimento comunitário e a esperança.

Ainda, extrapolando o objetivo de atenção às demandas comunitárias, o projeto mostrou-se potente no que diz respeito à formação dos educadores, os quais se dizem agradecidos com a experiência adquirida, em relação à troca de conhecimento, ao amadurecimento da perspectiva popular e a emancipação humana - pontos refletidos no trabalho de cada educador, nos mais diferentes âmbitos de formação.

\footnotetext{
$10 \mathrm{O}$ conceito de Educação é demasiadamente extenso no tocante das diferentes teorias que fazem dela instrumento e foco analítico. Na definição de Educação poder-se-ia elencar inúmeros autores para dimensiona-la. Entende-se que Moacir Gadotti traduz bem sua essência quando diz que: "A educação é um fenômeno complexo, composto por um grande número de correntes, vertentes, tendências e concepções, enraizadas em culturas e filosofias diversas. Como toda educação é política, como nos ensinou Paulo Freire, ela não é neutra, pois, necessariamente, implica princípios e valores que configuram uma certa visão de mundo e de sociedade" (2012, p. 10).
} 
Acredita-se que através desse projeto foi possível vislumbrar uma nova realidade em meio ao contexto político vigente, o qual desconsidera não apenas a Educação Popular e a imagem/legado de Paulo Freire, mas também todo e qualquer movimento que vai ao encontro de uma educação sensível, preocupada com grupos em situação de vulnerabilidade social, marginalizados e apartados de uma sociedade capitalista, imediatista e neoliberal ${ }^{11}$.

O ideal do PUPPN seguiu com sua prática no decorrer do ano de 2019, almejando cada vez mais atingir um público maior na comunidade em que se insere. No entanto, a cada indivíduo tocado pelas problematizações não apenas dos conteúdos necessários para a aprovação do ENEM, mas também do contexto histórico-social que hoje vigora, há o sentimento de gratidão e realização. É nesse sentido que se justifica a pertinência deste trabalho, o qual entende o espaço pré-universitário popular enquanto potente célula de resistência, pertencimento local e de fortalecimento de identidades.

Atualmente o Pré-universitário Popular Povo Novo, a partir de edital para obtenção de recursos, conquistou uma melhor estrutura física/material, contanto com prateleiras, impressora multifuncional, iluminação, recursos audiovisuais, livros etc. Devido à crise pandêmica, que por ora vigora em 2020, e pelo difícil acesso à internet e demais tecnologias na região, as atividades do projeto encontram-se em pausa - numa atenção às diretrizes governamentais.

\section{Referências}

ARROYO, Miguel G. Outros sujeitos, outras pedagogias. Petrópolis/RJ: Vozes, 2012.

BOFF, Leonardo. A águia e a galinha: uma metáfora da condição humana. Petrópolis/RJ: Vozes, 1997.

BRANDÃO, Carlos Rodrigues. O que é Educação? São Paulo: Editora Brasiliense, 1985. O que é Educação Popular. São Paulo: Brasiliense, 2006.

\footnotetext{
11 Ainda em tempo, embora em consideração final, ressalta-se neste trabalho o Marco de Referência da Educação Popular para as Políticas Públicas, oriundo da Secretaria-Geral da Presidência da República no ano de 2014, tendo Dilma Rousseff enquanto presidenta: "A Educação Popular tem um longo percurso no Brasil, a partir de um conjunto de práticas e experiências que se forjaram junto às classes populares, no chão das fábricas, em sindicatos, nas comunidades de base e igrejas, nas universidades, no campo, na cidade e na floresta, com os mais diferentes grupos, os trabalhadores, especialmente os em situação de pobreza, excluídos de seus direitos básicos como também em experiências que se realizam no âmbito da educação formal e da institucionalidade de governos municipais, estaduais e federal.” (CARVALHO, 2014, s/p)
} 
CARVALHO, G. Apresentação. In: SECRETARIA-GERAL da Presidência da República. Marco de Referência da Educação Popular para as Políticas Públicas. Brasília: SecretariaGeral, 2014.

FERREIRA, Marco Maia. Pedagogia Mediatizada: enfoque na interacção professor/aluno. Idiomático. Revista Digital de Didáctica PLNM. $\mathrm{n}^{\mathrm{o}}$ 1, abril de 2004. Disponível em http://cvc.instituto-camoes.pt/idiomatico/01/03.html . Acessado em 20 de março de 2019.

FEITOSA, Sonia Couto Souza. Método Paulo Freire: A reivenção de um Legado. Brasília: Liber Livro Editora, 2011.

FREIRE, Paulo. Pedagogia da Indignação: cartas pedagógicas e outros escritos. São Paulo: Paz e Terra, 2015. . Pedagogia do oprimido. Rio de Janeiro: Paz e Terra, 2011.

GADOTTI, Moacir. Educação Popular, Educação Social, Educação Comunitária: conceitos e práticas diversas, cimentadas por uma causa comum. Revista Dialogos: pesquisa em extensão universitária. IV Congresso Internacional de Pedagogia Social: domínio epistemológico. Brasília, v.18, n.1, dez, 2012.

GOHN, Maria da Glória. Educação popular na América Latina no novo milênio: impactos do novo paradigma. ETD - Educação Temática Digital, Campinas, v.4, n.1, p.53-77, dez. 2002. QUEIROZ, Maria Luiza Bertuline. A Vila do Rio Grande de São Pedro: 1737-1822. Rio Grande: FURG, 1987. 